\title{
Iran presidential candidate speaks out
}

\begin{abstract}
Biomedical researcher Mostafa Moin was a reformist candidate in Iran's 2005 presidential elections, following which Mahmoud Ahmadinejad became president. In a 2006 interview with Nature, Moin, a former minister for higher education and for science, argued that building a stronger civil and democratic society in Iran was key to the country's scientific development and it becoming a knowledge-based society. In an exclusive new interview, he discusses where the current situation leaves those ambitions.
\end{abstract}

\begin{abstract}
What is your assessment of Mahmoud Ahmadinejad's track record on science, and on academic freedom and social reform?

Scientific activity has stagnated. Students and young scientists have been discouraged. Pressure has been exerted on scientific forums and centres, and academic freedom restricted. The brain drain of elites has worsened. Administrations have been massively populated with people from the military and the security forces. We have an economic recession; destruction of ethical norms and public culture; and the scientific, political and cultural isolation of Iran in the international community. These are among the achievements of Ahmadinejad.
\end{abstract}

\section{Iran has a large scientific and} academic diaspora (see Nature doi:10.1038/news.2009.597; 2009) how best can it contribute during the current crisis?

Iranian scientists abroad have made, and will continue to make, a constructive contribution by throwing light on the false, suppressive and anti-development policies of Ahmadinejad and his government. The huge scientific capacity of Iranians abroad could also serve well in any serious effort to develop Iran, should a foresighted and compassionate government be established.

\section{In what ways could the international} scientific community help colleagues in Iran without meddling - or being seen to meddle - in Iran's internal affairs? Prominent universities and scientists worldwide can help through legitimate criticism of the Iranian government's treatment of students, academics, scientists and the people of Iran; its violations of citizens' constitutional rights and academic freedom.

I would like to say to my scientific colleagues wherever they are that while Iran, an ancient civilization, has its own cultural background and national interests,

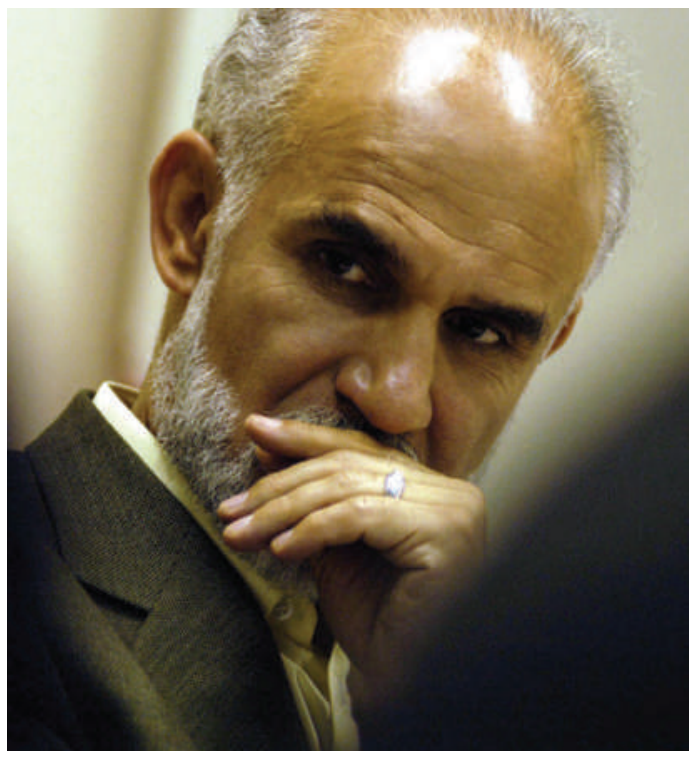

How might Iran's legitimate aspirations for nuclear power and technology be reconciled with international concern over its nuclear intentions?

Iran's nuclear issue has become both a political problem and an issue used for domestic political ends, resulting in an artificially tense atmosphere at the international level. But a government that derives its authority from a democratic election is better placed to also build trust at the international level - with a view to exploiting nuclear energy legally and peacefully, to both support the national interest and strengthen international cooperation.

In the $\mathbf{2 0 0 5}$ election, you were at one point considered a front-runner, but were beaten in the first round. Were you concerned about the election's

the nation and its academics wish to be productive and constructive members of the international community. They reject government adventurism and the creation of a climate of tension internationally.

In our last interview, you said that support by Iranian young people and women for the principles of a civil and democratic society were what would "shape Iran's future". Has that shaping moment come? Yes. The recent growth in Iranian women's and young people's political and social awareness has set the stage for their current demands for greater civil liberties, and structural and democratic reforms. The outcome of the 2005 presidential election, combined with the subsequent mismanagement of the government, has catalysed this process - and explains the $85 \%$ voter turnout in last month's presidential election, and the demand for change. The youth, and in particular the supporters of the reformist candidate Mir Hossein Mousavi, played a major role in creating the extraordinary enthusiasm and motivation surrounding the elections. I remain optimistic as to the role, and the movement, of Iran's youth. legitimacy? How do you plan to pursue your vision of a modern Iran?

I formally protested the illegitimacy and distortion of the first round and called for a ballot recount, but unfortunately the Council of Guardians rejected this request. Distrust towards the outcome of the recent elections has, I think, its roots in doubts with respect to the earlier election. My main mottos in the 2005 election were for the construction of a modern Iran through democracy, scientific development of the country and peace in the world. Fulfilment of the same remains among my basic ideals.

\section{Is an immediate national reconciliation the best way forwards?}

There can be no grounds for a national reconciliation in an atmosphere of public distrust. Trust and transparency must first be established by proper examination of the complaints of the presidential candidates. In any case, it seems inevitable that Iran must move towards a political system based on democracy, justice and moderation. Interview by Declan Butler

Additional questions and answers are available at http://tinyurl.com/kupapj. 